\title{
MACHINE LEARNING-THE FUTURE OF TECHNOLOGY
}

\author{
Anirban Chakraborty \\ Department of Artificial Intelligence \\ Lovely Professional University, Phagwara, Punjab, India
}

\begin{abstract}
Learning machine is a data analytical tool which automates the creation of the analytical model. It's an imaginary branch of knowledge focused on the assumption that machine data can be observed, trends and with that decisions can be taken with minimum human ability. Algorithms used for the machine learning submit data and based on that new results may be generated.
\end{abstract}

Keywords- Machine Learning, Clustering, Association, Classification, Identification.

\section{INTRODUCTION}

Machine Learning (ML) is an algorithm class which enhance the accuracy of software applications predicting effects without being coded directly. Machine learning is based on the creation of algorithms which can provide data input and use statistical analysis to predict an event when changing outputs are available. Machine Learning is very much successful in the last few years in application data prediction and increasing the strength of computation in recent years.

Machine learning is an excellent tool to understand Artificial Intelligence. It is an advanced part of Artificial Intelligence. It is the future of Artificial Intelligence. Some important characteristics of Machine Learning are:

\section{- Prediction}

Computer awareness can also be used in systems estimation. In the case of failure measurement, the system will predict the reason of failure.

\section{Image recognition}

Computer analysis may be used for face and photo identification. A different type of learning is accessible. Every user in the multi-person database have to register their facial photo.

\section{Speech Recognition}

It translates the words spoken by humans. Throughout the document, it is used when looking for voices and more.
Maker of speech, Speech dialing, request routing and systems are part of Interface Tests

\section{TYPES OF LEARNING}

\section{(A) SUPERVISED LEARNING}

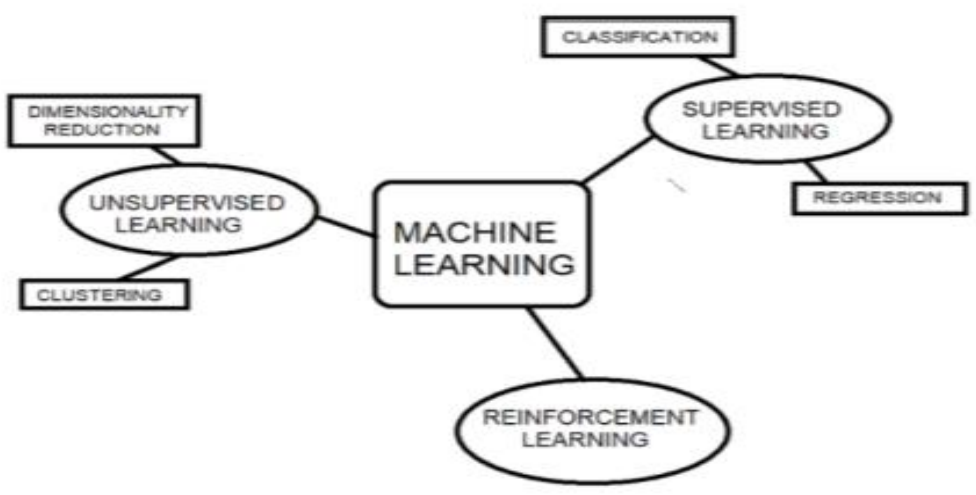

Fig.1. Supervised Learning Algorithm

An AI program with data is introduced in supervised learning that is labelled, indicating that any data is labelled with Wrong mark pr False logo. The objective is so closely linked to the mapping function that if you have fresh data input ' $x$ ' to estimate the ' $y$ ' for that data output variables. $x$ is an independent person. We practice our model on vector, y which is the dependent variable. The computer watches and knows the basis of the data collection. Linear and nonlinear contingent (y) relationship and Independent variable (x) and the meaning can be projected by this type of Learning.

\section{CLASSIFICATION}

When the output is an issue of classification, the type of attribute is "man," "actor" or "other"

"Infected" and "non-contaminated."

\section{REGRESSION}

The performance vector is a regression problem which is a true value like 'range' or 'temperature.' 


\section{International Journal of Engineering Applied Sciences and Technology, 2020 Vol. 5, Issue 1, ISSN No. 2455-2143, Pages 754-756 \\ Published Online May 2020 in IJEAST (http://www.ijeast.com)}

\section{(B) UNSUPERVISED LEARNING}

An AI framework is introduced in unattended learning, unlabeled data and system algorithms which acts as uncategorized data without pre-training on the results. The performance is subjected to regarding the algorithms that are labeled. The subject of a system uncontrolled curriculum is one way to check AI.

We've given our characters in the example below. The trend that's "laughing," "not laughing." throughout our training data, for the corresponding data, we do not provide any label. The unattended layout will separate the characters by examining the type of data and the underlying models' information construction or delivery is to discover more results.

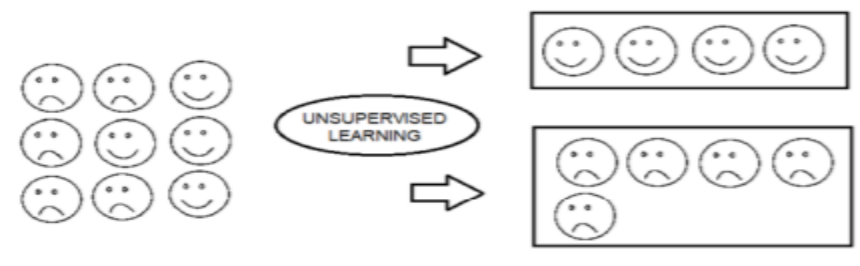

Fig.2. Unsupervised learning algorithm

\section{CLUSTERING}

You ought to create a clustering issue and find the inherent data groupings, for example grouping

by buying conduct, consumers.

\section{ASSOCIATION}

A cognitive difficulty of group law is where you would like to include laws explaining major portions of the information, like people purchasing $\mathrm{X}$, seem to purchase $\mathrm{Y}$ as well.

\section{(C) REINFORCEMENT LEARNING}

A learning algorithm or agent for strengthening learning learns from interacting with the surroundings. Training to change differs in a way that is from guided learning, training data has the key to response. The model is therefore trained with the right response though there is no answer but for reinforcement learning strengthens person who knows what to do in the job. It is necessary to learn in the absence of a data set may be from its past or may be from its knowledge.

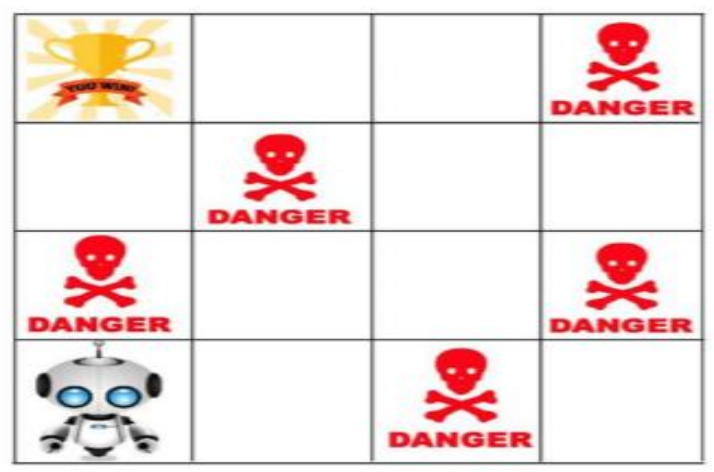

Fig.3. Robot, Prize and danger sign.
The picture above shows the device, award and sign of risk. The robot's purpose is to win the trophy and award and also stop the risks warning obstacles. The computer is going by seeking all feasible routes and then pick the best route. The least obstacles earns him the award. Every right step will offer a reward to the robot and deduct any wrong move on the robot's allowance. Total pay is measured that's the gem when it comes to the last award. This considers the bonuses which the agent gets. It improves its knowledge of the environment to choose the next action.

\section{CONCLUSION}

Machine Learning should be an asset for everyone. It is now widely used in every companies for convenience. It is the future of technology. Every large and complex calculations can be solved with Machine Learning very easily. It is the most advanced invention of Scientists.

\section{REFERENCES}

[1] Tope Komal , et al.; " Encryption and Decryption using Artificial Neural Network" , IARJSET , Vol. 2, Issue 4, April 2015 pp. 81-83

[2] Yousif Elfatih Yousif, Dr.Amin Babiker A/Nabi Mustafa, Dr.Gasm Elseed Ibrahim Mohammed" Review on Comparative Study of Various Cryptography Algorithms",IJARCSSE, Volume 5, Issue 4, April- 2015, pp. 51-55

[3] William Stallings, "Cryptography and Network Security: Principles and practices, Dorling Kindersley (india) pvt ltd., 4th edition(2009). [4] Ajay Pal Singh , Parvez Rahi " Performance Enhancement in Public key Cryptosystems for Security using RSA Algorithm " , IJARCCE , Vol. 5, Issue 11, November 2016, pp. 359-362

[5] Oludele Awodele, Olawale Jegede" Neural Networks and Its Application in Engineering ", InSITE, 2009

[6] Andrej Krenker, Janez Bešter and Andrej Kos " Introduction to the Artificial Neural Networks" , Methodological Advances and Biomedical Applications

[7] Manikandan.G, Rajendiran.P, Chakarapani.K, Krishnan.G, Sundarganesh.G, "A Modified Crypto Scheme for Enhancing Data Security", Journal of Theoretical and Advanced Information Technology, Jan 2012.

[8] A.Nadeem, "A performance comparison of data encryption algorithms", IEEE information and communication technologies, pp.84-89, 2006.

[9] Diaasalama, Abdul kader, MohiyHadhoud, "Studying the Effect of Most Common Encryption Algorithms", International Arab Journal of etechnology, vol 2,no.1,January 2011.

[10] Atul Kahte.Cryptography and Network Security.Tata Mcgraw Hill, 2007. 
[11] Shasi Mehlrotra seth, Rajan Mishra “ ComparativeAnalysis of Encryption Algorithms For Data Communication", IJCST Vol. 2, Issue 2, June 2011.

[12] Wuling Ren. A Hybrid Encryption Algorithm Based on DES and RSA in Bluetooth Communication. Second International Conference on Modeling, Simulation and Visualization Methods (WMSVM), 2010.

[13] Natalie, R. (2015). 14 Main Advantages and Disadvantages of Computer Networking, https://greengarageblog.org/14-main-advatages-and-ofcomputer-networking.

[14] Anshika, G. (2013). Types of Area Networks-LAN, MAN and WAN.https://www.geeksforgeeks.org/types-ofareanetworks-lan-man-and-wan/.

[15] Atayero, A., A., Alatishe, A., S., and Iruemi, J., O. (2012). Modeling and Simulation of a University LAN in OPNET Modeler Environment, International Journal of Emerging Technology and Advanced Engineering (IJETAE), Vol. 2250-2459, pp. 1-4.

[16] Singh, H., Singh, S., Malhotra, R. (2013). Modeling, Evaluation and Analysis of Ring Topology for Computer Applications Using Simulation, International Journal of Computer Science and Mobile Computing, IJCSMC, Vol. 2, No. 1, pp.1 - 10.

[17] Elechi, O., O. (2014). Design and Simulation of Wireless Local Area Network for Administrative Office Using OPNET Network Simulator: A Practical Approach, Information and Knowledge Management, Vol. 4, No. 10, pp. 27-33. 